\title{
Immediate Effects of Bilateral Sacroiliac Joint Manipulation on Plantar Pressure Distribution in Asymptomatic Participants
}

\author{
Roberto Méndez-Sánchez, PT, DO,,2 Javier González-Iglesias, PT, DO, PhD, 2,3 \\ José Luis Sánchez-Sánchez, PT, PhD, and Ana Silvia Puente-González, PT, CO 1,2
}

\begin{abstract}
Objective: To investigate the immediate effects of manipulation of bilateral sacroiliac joints (SIJs) on the plantar pressure distribution in asymptomatic participants in the standing position.

Design: Randomized, controlled, double-blind clinical trial.

Participants: Sixty-two asymptomatic men and women (mean age, 20.66 \pm 2.56 years) randomly assigned to 2 groups.

Interventions: The experimental group underwent mobilization without tension of the hips in the supine position and high-velocity, low-amplitude manipulation in the SIJs bilaterally. The control group underwent only mobilization, without tension of the hips in supine position.

Outcome Measures: Pre- and postintervention outcomes measured by an assessor blinded to the treatment allocation of the participants included a baropodometric analysis performed by using a force platform. Baseline between-group differences were examined with a Kolmogorov-Smirnov test. A chi-square test was used for categorical data. Analysis of covariance (ANCOVA) was used to assess differences between groups, with the preintervention value as covariant (95\% confidence level).

Results: At baseline, no variables significantly differed between groups. Baropodometric analysis showed statistically significant differences in the location of the maximum pressure point in the experimental group $(p=0.028)$. Pre- and postintervention analysis with ANCOVA showed statistically significant differences between both groups in the left hindfoot load percentage (interaction $p=0.0259$; ANCOVA $p=0.0277$ ), right foot load percentage (ANCOVA $p=0.0380$ ), and surface of the right forefoot (interaction $p=0.0038$ ). There was also a significant effect in the variables that analyze the entire foot (left foot: surface [interaction $p=0.0452$ ], percentage of load [ANCOVA $p=0.0295]$ ) and between both groups (right foot: weight [interaction $p=0.0070 ;$ ANCOVA $p=0.0296]$ ).

Conclusions: Sacroiliac joint manipulation applied bilaterally in asymptomatic persons resulted in immediate changes in load distribution on plantar support in the standing position. Study limitations and suggestions for future studies are discussed.
\end{abstract}

\section{Introduction}

$\mathbf{T}$ HE POSTURAL CONTROL SYSTEM is a complex sensory interaction mechanism that integrates kinesthetic memory and visual, tactile, proprioceptive, and statoacoustic information. ${ }^{1-7}$ After analysis, the central nervous system provides a response or changes the postural attitude, starting the motor control system. ${ }^{5,8,9}$ These motor reactions are interventions, often subtle, with three aims: maintain posture, generate anticipatory responses to voluntary movements (feed-forward), or provide an adaptive response to achieve both postural and joint stability. ${ }^{8-11}$

The sacroiliac joints (SIJs) are a key element in maintaining the standing posture. The center of mass, ${ }^{9}$ also called the center of gravity, ${ }^{6}$ is located in the pelvis. Its stability is essential for the proper transmission of forces to the lower

\footnotetext{
${ }^{1}$ Department of Physical Therapy, Universidad de Salamanca, Salamanca, Spain.

${ }^{2}$ Madrid School of Osteopathy, Madrid, Spain.

${ }^{3}$ Clinic of Physical Therapy Integral Candás, Candás, Asturias, Spain.
} 
limbs and hence the distribution of load between the feet. $^{6,12,13}$ It is also the confluence of upward and downward forces, with frequent restrictions. ${ }^{12-14}$ Sacroiliac dysfunction is present not only in symptomatic patients ${ }^{14}$ but also in asymptomatic people. ${ }^{15}$ These joint restrictions may result in both ascending and descending muscular and ligamentous imbalance, ${ }^{5}$ as has been shown in the spinal muscles, ${ }^{16}$ altering postural stability. ${ }^{17}$

Therefore, sacroiliac dysfunction, like other lower-limb disorders, can alter the standing position and thus affect the transmission of forces and normal plantar pressure distribution; ${ }^{18}$ as in people with chronic low back pain, the mechanism in feed-forward activation is impaired. ${ }^{19}$ Some authors have reported that the greater pressure during the standing position is normal in the hindfoot. ${ }^{18,20-22}$

Several studies have used computerized baropodometry to assess alterations in lower limbs. ${ }^{23-26}$ This instrument has also been used to analyze the different effects of manual therapy techniques on body changes in relation to the support on the ground, both in static $24,25,27,28$ and in dynamic $^{29}$ settings, with the aim of assessing different variables on postural oscillations, plantar supporting areas, and pressure points. These are objective and reproducible assessment methods. ${ }^{30}$

High-velocity, low-amplitude (HVLA) spinal manipulations affect the proprioceptive system. ${ }^{11,31-33}$ Some studies showed proprioceptive changes in the upper extremity after manipulation of the cervical spine. ${ }^{34-36}$ This intervention appears to normalize the alterations of the afferent information in the somatosensory system. ${ }^{35} \mathrm{Haa}-$ vik et al. (2011) suggest that improved spinal function after a manipulation produces a suitable and accurate integration of afference in the propioception system. ${ }^{34}$ Referring to the SIJs, it has been observed that manipulation decreases the H-reflex, evaluated by electromyography and tibial nerve stimulation in the soleus muscle, ${ }^{37}$ and decreases muscle tone. ${ }^{38}$ Grassi et al. (2011) observed immediate and weekly changes in load standing distribution after a unilateral SIJ manipulation. ${ }^{24}$

The aim of the current study was to investigate the immediate effects of bilateral SIJ manipulation on the plantar pressure distribution in asymptomatic individuals in the standing position.

\section{Materials and Methods}

\section{Participants}

This randomized, controlled, double-blind clinical trial sought to investigate the immediate changes seen in the standing position after bilateral manipulation of SIJs on plantar support and stability in asymptomatic persons. The study included 62 participants of both sexes, age 18-30 years (mean, 20.66 \pm 2.56 years). Exclusion criteria were as follows: (1) abnormalities that alter balance; (2) deformities, orthopedic injuries, or traumatic history in the lower limbs or spine; (3) ventilatory disorders; (4) pain during the study; (5) receipt of physical therapy in the lower limbs or spine in the previous 6 months; (6) participation in vigorous physical activity before the measurements; and (7) contraindication to HVLA manipulation. Participants were randomly assigned to 2 groups: the experimental group $(n=31)$ and the control group $(n=31)$.

\section{Protocol}

The participants voluntarily signed informed consent forms for inclusion in the study. They were asked not to perform any physical activity in the 24 hours before the study. Physical analysis was performed to evaluate anthropometric properties (mean body-mass index [BMI], $22.89 \pm 3.18 \mathrm{~kg} / \mathrm{m}^{2}$ ). An initial baropodometric assessment before the intervention was performed by a blinded assessor.

Study participants were placed on a force platform to collect data for the measured variables. After the first measurement the therapist, without knowledge of previous assessments, distributed the participants randomly into two groups. The therapist applied a different intervention in the experimental and control groups. The experimental group received the placebo technique and an HVLA manipulation in the SIJs bilaterally; the control group underwent only the placebo technique. Postintervention measurement on the force platform was performed by the blinded assessor in the same way 5 minutes after the procedure in each group.

\section{Evaluations}

A baropodometric analysis was performed by using a diagnostic support force platform (Modular Electronic Baropodometer, Diasu SRL, Italy) with a capture area of $120 \times 40 \mathrm{~cm}, 1600$ sensors, and $200 \mathrm{~Hz}$ of frequency.

The participants stood barefoot on the force platform, with arms relaxed in extension of the body and feet slightly apart $(5-10 \mathrm{~cm})$. Data were measured for 1 minute. Before the evaluation began, participants were instructed to "Be as still as possible, breathe normally, stare at a point (located $5 \mathrm{~m}$ in front of [you]), do not tighten the jaw, not talk and hold in that position until I tell you the measurement has finished."

The outcome measures analyzed before and after the intervention were surface and percentage of load on each forefoot and hindfoot and each foot in its entirety and the location of the maximum pressure point on the plantar support.

\section{Reliability study}

Before the study began, a reliability study was conducted with 10 asymptomatic participants. A baropodometric analysis was performed as described earlier, and three independent reviewers analyzed the results. The intraclass correlation coefficient showed high interexaminer reliability, with all variables above 0.7 (average intraclass correlation coefficient for all variables, 0.83 [95\% confidence interval, 0.58-0.93]).

\section{Intervention}

In the experimental group, mobilization of the hips without tension was applied in the supine position and HVLA manipulation was applied in the SIJs bilaterally. Each side was manipulated with the participant lying on the contralateral side to be treated, a complete rachis rotation was adjusted, and hip flexion tension focus was applied in the SIJ. The forearm was placed in contact with the iliac to manipulate along the joint. After this position, HVLA manipulation to open the SIJ was done (Fig. 1). 


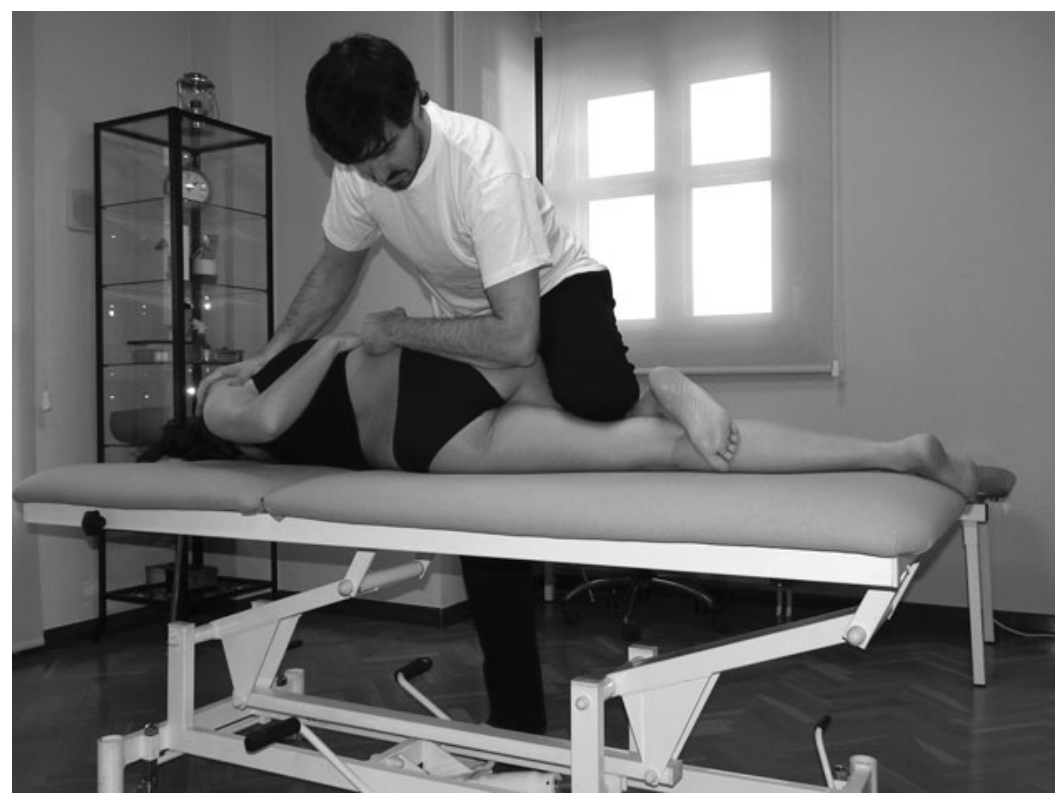

FIG. 1. Global sacroiliac joint manipulation technique.

In the control group, only the placebo technique (mobilization without tension of the hips in the supine position) was applied.

\section{Statistical analysis}

Data were analyzed by using the SPSS software package (version 15.0; SPSS, Inc., Chicago, Illinois). Means and standard deviations were calculated for each variable. A normal distribution of quantitative data was assessed by means of the Kolmogorov-Smirnov test $(p>0.05)$. A chisquare test was used for categorical data. Analysis of covariance (ANCOVA) was used to assess differences between groups, with the preintervention value as covariant, group as the independent variable, and postintervention value as the dependent variable. Because of interactions between the regression lines for each group in some variables, this condition has been contrasted by introducing an interaction term in the model to take into account that the growth of the dependent variable differs in each group. The statistical analysis was conducted at a $95 \%$ confidence level. A $p$-value $<0.05$ was considered to indicate statistical significance in all analyses.

\section{Results}

The experimental group consisted of 31 participants (21 women and 10 men), with a mean age of $21.210 \pm 2.735$ years and a BMI of $22.92 \pm 3.75 \mathrm{~kg} / \mathrm{m}^{2}$. The control group consisted of 31 participants ( 22 women and 9 men), with a mean age of $20.11 \pm 2.29$ years and a BMI of 22.87 $2.55 \mathrm{~kg} / \mathrm{m}^{2}$. No significant differences between groups in any variables at baseline were shown by the KolmogorovSmirnov test.

Regarding baropodometric data, the location of the maximum pressure point on the plantar support during measurement was significantly different in the experimental group ( $p=0.028)$ (Table 1). After the SIJ manipulation, the percentage of participants with maximum pressure point in the forefoot decreased from $25.8 \%$ to $9.7 \%$. In the control group, this percentage increased from $16.1 \%$ to $25.8 \%$.

Differences in means of variables evaluated between preand postintervention are interesting (Table 2), and ANCOVA showed statistically significant differences between both groups for some variables (Table 3). In the hindfoot load percentage there were significant differences; in the left foot, both in the interaction $(p=0.0259)$ and in ANCOVA $(p=0.0277)$ between groups, this value decreased in the experimental group. In the right foot, ANCOVA showed a statistically significant $(p=0.0380)$ increase in the experimental group. The surface of the right forefoot showed statistically significant differences for the interaction between groups $(p=0.0038)$, decreasing more in the experimental group than in the control group.

After the SIJ manipulation, the variations in surface, percentage of load, and weight of the feet were different in each group. In relation to the variables for the entire foot, first for the left foot, the supporting surface increased in both groups, while the percentage of load and the weight decreased in the experimental group and increased in the control group. The three variables showed significant differences between the groups: the surface variable on the interaction between the groups $(p=0.0452)$, the percentage of load variable on ANCOVA $(p=0.0295)$, and the weight

Table 1. Chi-Square Test (Location of the Maximum Pressure Point on the Plantar Support)

\begin{tabular}{lrr}
\hline Group & Value & p-Value \\
\hline Experimental group & & \\
Chi-square & 14,135 & $0.028^{*}$ \\
Participants $(n)$ & 31 & \\
Control group & & \\
$\quad$ Chi-square & 8584 & 0.477 \\
Participants $(n)$ & 31 & \\
\hline
\end{tabular}

*Statistically significant difference; $p<0.05$. 
Table 2. Means and Means Differences Pre-Postintervention for Variables of Each Foot by Groups

\begin{tabular}{|c|c|c|c|c|c|c|c|}
\hline \multirow[b]{2}{*}{ Outcome measures } & \multirow{2}{*}{$\begin{array}{c}\text { Mean } \\
\text { preintervention }\end{array}$} & \multirow{2}{*}{$\begin{array}{c}\text { Mean } \\
\text { postintervention }\end{array}$} & \multirow{2}{*}{$\begin{array}{c}\text { Mean } \\
\text { difference } \\
\text { pre-post }\end{array}$} & \multirow[b]{2}{*}{$S D$} & \multirow[b]{2}{*}{$S E$} & \multicolumn{2}{|c|}{$95 \% C I$} \\
\hline & & & & & & Lower & Upper \\
\hline \multicolumn{8}{|l|}{ Experimental group } \\
\hline LFF: surface $\left(\mathrm{mm}^{2}\right)$ & 45.77 & 44.03 & 1.74 & 5.67 & 1.02 & -0.34 & 3.82 \\
\hline LFF: load $(\%)$ & 19.84 & 19.39 & 0.45 & 3.29 & 0.59 & -0.76 & 1.66 \\
\hline LHF: surface $\left(\mathrm{mm}^{2}\right)$ & 50.68 & 50.26 & 0.42 & 4.36 & 0.78 & -1.18 & 2.02 \\
\hline LHF: load $(\%)$ & 28.55 & 28.32 & 0.23 & 4.66 & 0.84 & -1.48 & 1.94 \\
\hline RFF: surface $\left(\mathrm{mm}^{2}\right)$ & 53.58 & 50.42 & 3.16 & 7.24 & 1.30 & 0.51 & 5.82 \\
\hline RFF: load (\%) & 24.00 & 23.16 & 0.84 & 4.82 & 0.87 & -0.93 & 2.61 \\
\hline RHF: surface $\left(\mathrm{mm}^{2}\right)$ & 51.65 & 51.26 & 0.39 & 6.32 & 1.14 & -1.93 & 2.71 \\
\hline RHF: load (\%) & 27.61 & 29.13 & -1.52 & 3.35 & 0.60 & -2.74 & -0.29 \\
\hline LF: surface $\left(\mathrm{mm}^{2}\right)$ & 93.87 & 94.29 & -0.42 & 14.82 & 2.66 & -5.86 & 5.02 \\
\hline LF: load $(\%)$ & 48.39 & 47.71 & 0.68 & 5.11 & 0.92 & -1.20 & 2.55 \\
\hline LF: weight (kg) & 30.82 & 30.12 & 0.70 & 3.61 & 0.65 & -0.63 & 2.03 \\
\hline $\mathrm{RF}:$ surface $\left(\mathrm{mm}^{2}\right)$ & 102.61 & 101.68 & 0.94 & 19.40 & 3.48 & -6.18 & 8.05 \\
\hline RF: load $(\%)$ & 51.61 & 52.29 & -0.68 & 5.11 & 0.92 & -2.55 & 1.20 \\
\hline RF: weight (kg) & 32.54 & 33.24 & -0.70 & 3.61 & 0.65 & -2.03 & 0.63 \\
\hline \multicolumn{8}{|l|}{ Control group } \\
\hline LFF: surface $\left(\mathrm{mm}^{2}\right)$ & 47.13 & 46.32 & 0.81 & 6.80 & 1.22 & -1.69 & 3.30 \\
\hline LFF: load $(\%)$ & 21.06 & 20.94 & 0.13 & 3.80 & 0.68 & -1.27 & 1.52 \\
\hline LHF: surface $\left(\mathrm{mm}^{2}\right)$ & 50.19 & 51.48 & -1.29 & 4.38 & 0.79 & -2.90 & 0.32 \\
\hline LHF: load $(\%)$ & 27.00 & 29.48 & -2.48 & 3.89 & 0.70 & -3.91 & -1.06 \\
\hline RFF: surface $\left(\mathrm{mm}^{2}\right)$ & 51.48 & 50.32 & 1.16 & 10.05 & 1.81 & -2.53 & 4.85 \\
\hline RFF: load $(\%)$ & 22.52 & 21.29 & 1.23 & 4.29 & 0.77 & -0.35 & 2.80 \\
\hline RHF: surface $\left(\mathrm{mm}^{2}\right)$ & 54.77 & 54.42 & 0.35 & 4.88 & 0.88 & -1.43 & 2.14 \\
\hline RHF: load $(\%)$ & 29.55 & 28.94 & 0.61 & 3.19 & 0.57 & -0.56 & 1.78 \\
\hline LF: surface $\left(\mathrm{mm}^{2}\right)$ & 97.32 & 97.81 & -0.48 & 9.09 & 1.63 & -3.82 & 2.85 \\
\hline LF: load $(\%)$ & 48.06 & 49.77 & -1.71 & 4.87 & 0.88 & -3.50 & 0.08 \\
\hline LF: weight (kg) & 30.60 & 31.74 & -1.14 & 3.05 & 0.55 & -2.26 & -0.02 \\
\hline $\mathrm{RF}$ : surface $\left(\mathrm{mm}^{2}\right)$ & 106.26 & 104.42 & 1.84 & 11.29 & 2.03 & -2.30 & 5.98 \\
\hline RF: load $(\%)$ & 51.94 & 50.23 & 1.71 & 4.87 & 0.88 & -0.08 & 3.50 \\
\hline RF: weight (kg) & 33.00 & 31.87 & 1.14 & 3.05 & 0.55 & 0.02 & 2.26 \\
\hline
\end{tabular}

CI, confidence interval; LF, left foot; LHF, left hindfoot; LFF, left forefoot; RF, right foot; RHF, right hindfoot; RFF, right forefoot; SD, standard deviation; SE, standard error.

variable on both the interaction $(p=0.0466)$ and ANCOVA $(p=0.0142)$.

In the right foot, the supporting surface in the control group decreased twice the amount seen in the experimental group. The percentage of load and the weight again behaved differently in both groups, increasing in the experimental group and decreasing in the control group, with significant differences for the weight variable both in the interaction $(p=0.0070)$ and ANCOVA $(p=0.0296)$.

\section{Discussion}

The results indicate that the changes in measurements in both groups are different, demonstrating that bilateral manipulation of SIJs produces changes in some baropodometric variables, with statistical significance at $p<0.05$. This observation reinforces the results of other studies reporting baropodometric variations after the application of HVLA techniques. ${ }^{24,25}$ However, a few studies that evaluated baropodometric changes after HVLA techniques showed even fewer changes after SIJ manipulation.

This study was performed in asymptomatic participants, as was done in other studies, ${ }^{24,27,39}$ knowing that some of these may have SIJ dysfunction. ${ }^{15}$ Asymptomatic participants were enrolled to avoid inclusion of those with an active central sensitization clinical condition. ${ }^{40}$
There is some controversy in the literature regarding the effectiveness of diagnostic tests for palpation and mobility of the SIJs. Some authors have not demonstrated the effectiveness of these tests, ${ }^{41-44}$ whereas others report efficacy in some combination of tests. ${ }^{45}$ Therefore, without performing a preliminary test in these asymptomatic participants, the current study applied a bilateral SIJ intervention, as was done in other studies, ${ }^{27,28}$ because SIJ manipulation affects muscle tone only of the ipsilateral lower limb muscles. ${ }^{38}$

Schiffer (2001) has shown that $60 \%$ of the weight support should be on the hindfoot and $40 \%$ on the forefoot, with a tolerance of $\pm 4 \% .{ }^{20}$ Other authors also claim that maximum load should be on the hindfoot. ${ }^{18,20-22,46}$ This is consistent with the results obtained in the current study, in which both the experimental group and the control group showed an increase in the hindfoot percentage of load on postintervention measurement. However, the percentage of participants in the experimental group with the point of maximum pressure in the hindfoot after manipulation was significantly greater, increasing from $74.2 \%$ to $90.4 \%$, whereas in the control group this percentage decreased from $83.9 \%$ to $74.2 \%$. Gravante and colleagues (2005) obtained results in persons with normal foot architecture, wherein the forefoot and hindfoot had a percentage close to $50 \%$ and the percentage of claw feet in the hindfoot decreased to $48.5 \%$ among women and $44.9 \%$ among men. ${ }^{23}$ Other authors have 
Table 3. Effectiveness of Bilateral Sacroiliac JOINT MANIPULATION: INTERGROUP COMPARISON With Analysis of Covariance

\begin{tabular}{|c|c|c|c|c|}
\hline Outcome measures & $D F$ & Statistic & $S E$ & $\mathrm{p}$-Value \\
\hline \multirow[t]{2}{*}{ LFF: surface $\left(\mathrm{mm}^{2}\right)$} & 58 & tion & 0.08 & 0.5693 \\
\hline & & ANCOVA & 0.71 & 0.3370 \\
\hline RFF: surface $\left(\mathrm{mm}^{2}\right)$ & 58 & $\begin{array}{l}\text { Interaction } \\
\text { ANCOVA }\end{array}$ & $\begin{array}{l}0.10 \\
0.95\end{array}$ & $\begin{array}{l}0.0038^{*} \\
0.5743\end{array}$ \\
\hline \multirow{2}{*}{ LFF: load (\%) } & 58 & Interaction & 0.09 & 0.6381 \\
\hline & & ANCOVA & 0.41 & 0.3360 \\
\hline \multirow[t]{2}{*}{ RFF: load (\%) } & 58 & Interaction & 0.10 & 0.7297 \\
\hline & & $\mathrm{AI}$ & 0.50 & 0.2662 \\
\hline LHF: surface $\left(\mathrm{mm}^{2}\right)$ & 58 & $\begin{array}{l}\text { In } \\
\text { Al }\end{array}$ & $\begin{array}{l}0.05 \\
0.52\end{array}$ & \\
\hline \multirow[t]{2}{*}{ RHF: surface $\left(\mathrm{mm}^{2}\right)$} & 58 & Interaction & 0.07 & 0.3613 \\
\hline & & ANCOVA & 0.68 & 0.6288 \\
\hline \multirow[t]{2}{*}{ LHF: load (\%) } & 58 & Inter & 0.09 & $59 *$ \\
\hline & & ANC & 0.49 & $0.0277 *$ \\
\hline \multirow[t]{2}{*}{ RHF: load (\%) } & 58 & Intera & 0.12 & 0.3072 \\
\hline & & ANCOVA & 0.43 & $0.0360 *$ \\
\hline \multirow[t]{2}{*}{ LF: surface $\left(\mathrm{mm}^{2}\right)$} & 58 & Interaction & 0.06 & $0.0452 *$ \\
\hline & 58 & & $\begin{array}{l}1.18 \\
0.08\end{array}$ & \\
\hline RF: surface $\left(\mathrm{mm}^{2}\right)$ & 50 & ANCOVA & $\begin{array}{l}0.00 \\
1.63\end{array}$ & 0.8285 \\
\hline \multirow[t]{2}{*}{ LF: load (\%) } & 58 & Interaction & 0.10 & 0.9336 \\
\hline & & ANC & 0.49 & $0.0295 *$ \\
\hline \multirow[t]{2}{*}{ RF: load (\%) } & 58 & Interaction & 0.08 & 0.4014 \\
\hline & & ANC & 1.63 & 0.8285 \\
\hline \multirow[t]{2}{*}{ LF: weight (kg) } & 58 & Interaction & 0.06 & $0.0466^{*}$ \\
\hline & & ANCOVA & 0.35 & $0.0142 *$ \\
\hline \multirow[t]{2}{*}{ RF: weight (kg) } & 58 & Interaction & 0.07 & $0.0070 *$ \\
\hline & & & 0.40 & $0.0296^{*}$ \\
\hline
\end{tabular}

* Statistically significant difference; $p<0.05$.

ANCOVA, analysis of covariance; DF, degrees of freedom.

shown different results, with a higher percentage of pressure in the forefoot than in the hindfoot, but this study was conducted among patients with an ankle sprain. ${ }^{25}$

Other studies that evaluated the effects of manipulations by using force platforms obtained variations in fluctuations of center of gravity that have affected support surface and load distribution.

In an uncontrolled trial, Grassi et al. (2011) found a significantly different decrease in pressure peak between both feet after sacroiliac dysfunction manipulation. However, differences in the areas of support were not significant. ${ }^{24}$

Another controlled trial by López et al. (2007) showed that after manipulation of the talo-crural joint in patients with ankle sprain, the load percentage in forefoot and hindfoot bilaterally changed significantly. However, unlike in the current study, the forefoot loading percentage increased and the hindfoot loading percentage decreased, with postintervention values of $66.34 \%$ in the forefoot and $33.66 \%$ in the hindfoot. ${ }^{25}$

Alburquerque and colleagues (2009), in a controlled trial with bilateral manipulation of the talo-crural joints in asymptomatic individuals, noticed a significant decrease in the range of anterior-posterior oscillation, as well as changes in the surface area of displacement of the center of gravity. ${ }^{27}$

In the current study, load distribution significantly differed between forefoot and hindfoot; more pressure was brought to the hindfoot after the intervention, while the lateral distribution, by changing load from left to right between feet, showed decreasing significant differences in the load percentage (ANCOVA, $p=0.0295$ ) and in the supporting surface (ANCOVA interaction, $p=0.0452$ ) of the left foot. These findings differ from those of Grassi and colleagues (2011), ${ }^{24}$ who reported that peak pressure modifications were not accompanied by support surface changes.

The results obtained-that SIJ manipulation in asymptomatic persons modifies the plantar pressure distribution with decreasing weight on the forefoot-suggests that it would be interesting and convenient in future studies to analyze this intervention in individuals in whom an increased forefoot pressure may be a problem, such as people with metatarsal pain ${ }^{47}$ or diabetes. ${ }^{48,49}$ It would also be interesting to do a follow-up study to prove its lasting effect on postural control.

If manipulation-mobilization did not alter the position between the sacrum and the ilium, as evaluated by roentgen stereophotogrammetric analysis in the standing position, ${ }^{50}$ the variation in force transmission on the plantar support can be due to other changes after bilateral manipulation of the SIJs, such as the change in sensory integration (afferent) ${ }^{11,32,34-36}$ or in the efficiency of the motor control sys-

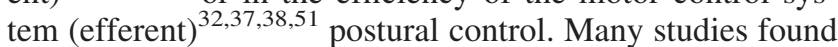
distance effects in the musculoskeletal system after HVLA spinal manipulations. ${ }^{34,36-38,51}$ This is consistent with the significant changes found in the current study in some variables, such as load distribution and support surface after the bilateral SIJ intervention.

The current study does have some limitations. Both intrasubject variability baropodometric data and the sample size used may have influenced the differences found between the groups, thereby explaining the lack of additional statistically significant differences. Furthermore, conducting the study in asymptomatic individuals makes it necessary to develop future studies with participants who have weight distribution postural alterations to the lower limbs.

In conclusion, HVLA manipulation of the SIJs applied bilaterally in asymptomatic participants showed immediate changes in load distribution on the plantar support in the standing position. This redistribution is probably obtained by homogenization between both feet of the support, reducing the support on the forefeet and increasing support on the hindfeet, accompanied by a lateral displacement of the load and weight distribution.

\section{Author Disclosure Statement}

No competing financial interests exist.

\section{References}

1. Baron JB, Ushio N, Tangapregassom MJ. Orthostatic postural activity disorders recorded by statokinesimeter in post-concussional syndromes: oculomoter aspect. Clin Otolaryngol Allied Sci 1979;4:169-174.

2. Baron JB, Ushio N, Noto R. Oculo-nuco-vestibulo-spinal system regulating tonic postural activity; statokinesimetric study. Agressologie 1974;15:395-400. 
3. Morningstar MW, Pettibon BR, Schlappi H, et al. Reflex control of the spine and posture: a review of the literature form a chiropractic perspective. Chiropr Osteopath 2005; 13:16.

4. Yasuda $\mathrm{T}$, Nakagawa $\mathrm{T}$, Inoue $\mathrm{H}$, et al. The role of the layrinth, proprioception and plantar mechanosensors in the maintenance of an upright posture. Eur Arch Otorhinolaryngol 1999;256:27-32.

5. Riemann BL, Lephart SM: The sensorimotor system. I. The physiologic basis of functional joint stability. J Athl Train 2002;37:71-79.

6. Winter DA. Human balance and posture control during standing and walking. Gait Posture 1995;3:193-214.

7. Peterka RJ. Sensorimotor integration in human postural control. J Neurophysiol 2002;88:1097-1118.

8. Riemann BL, Lephart SM: The sensorimotor system. II. The role of proprioception in motor control and functional joint stability. J Athl Train 2002;37:80-84.

9. Geoffrey MJ. Posture. In: Kandel ER, Schwartz JH, Jessell TM. Principles of Neuroscience. Madrid: McGraw HillInteramericana; 2001:816-32.

10. Santos MJ, Kanekar N, Aruin AS. The role of anticipatory postural adjustments in compensatory control of posture: 2 . Biomechanical analysis. J Electromyogr Kinesiol 2010; 20: 398-405.

11. Haavik H, Murphy B. The role of spinal manipulation in addressing disordered sensorimotor integration and altered motor control. J Electromyogr Kinesiol 2012;22:768-776.

12. Pel JJ, Spoor CW, Pool-Goudzwaard AL, et al. Biomechanical analysis of reducing sacroiliac joint shear load by optimization of pelvic muscle and ligament forces. Ann Biomed Eng 2008;36:415-424.

13. Snijders CJ, Vleeming A, Stoeckart R. Transfer of lumbosacral load to iliac bones and legs. Part 1: biomechanics of self-bracing of the sacroiliac joints and its significance for treatment and exercise. Clin Biomech 1993;8:285-294.

14. Maigne JY, Aivaliklis A, Pfefer F. Results of sacroiliac joint double block and value of sacroiliac pain provocation tests in 54 patients with low back pain. Spine 1996;21:1889-1892.

15. Dreyfuss P, Dryer S, Griffin J, et al. Positive sacroiliac screening tests in asymptomatic adults. Spine 1994;19: 1138-1143.

16. Brumagne S, Cordo P, Lysens R, et al. The role of paraspinal muscle spindles in lumbosacral position sense in individuals with and without low back pain. Spine 2000; 25:989-994.

17. Luoto S, Taimela S, Hurri H, et al. Psychomotor speed and postural control in chronic low back pain patients. A controlled follow-up study. Spine 1996;21:2621-2627.

18. Jonely H, Brismée JM, Sizer PS Jr, James CR. Relationships between clinical measures of static foot posture and plantar pressure during static standing and walking. Clin Biomech 2011;26:873-879.

19. Hodges PW, Richardson CA. Altered trunk muscle recruitment in people with low back pain with upper limb movement at different speeds. Arch Phys Med Rehabil 1999;80:1005-1012.

20. Schiffer R. Clinical use of electronic baropodometry system in clinical laboratory of posturology [Italian]. Notiziario Ordine dei Medici Chirurghi e degli Odontoiatri della Provincia di Cuneo, Italy. 2001;11. Online document at: www .neuroequilibrio.it/Biometria\%20Digitalizzata/Ordine\%20dei\% 20Medici\%20Utilizzo\%20Baropodometria\%20Elettronica\%20 Sistema\%20Clinico.pdf Accessed December 18, 2012.
21. Kapandji AI. Physiology of the Joints. Volume 2: Lower Limb [Spanish]. 6th ed. Madrid: Editorial Médica Panamericana; 2012.

22. Luger EJ, Nissan M, Karpf A, et al. Patterns of weight distribution under the metatarsal heads. J Bone Joint Surg Br 1999;81:199-202.

23. Gravante G, Pomara F, Russo G, et al. Plantar pressure distribution analysis in normal weight young women and men with normal and claw feet: a cross-sectional study. Clin Anat 2005;18:245-250.

24. Grassi Dde O, de Souza MZ, Ferrareto SB, et al. Immediate and lasting improvements in weight distribution seen in baropodometry following a high-velocity, low-amplitude thrust manipulation of the sacroiliac joint. Man Ther. 2011;16:495-500.

25. López-Rodríguez S, Fernández de-Las-Peñas C, Alburquerque-Sendín $\mathrm{F}$, et al. Immediate effects of manipulation of the talocrural joint on stabilometry and baropodometry in patients with ankle sprain. J Manipulative Physiol Ther 2007;30:186-192.

26. Sawacha Z, Gabriella G, Cristoferi G, et al. Diabetic gait and posture abnormalities: a biomechanical investigation through three dimensional gait analysis. Clin Biomech 2009;24:722-728.

27. Alburquerque-Sendín F, Fernández-de-las-Peñas C, Santosdel-Rey M, Martín-Vallejo FJ. Immediate effects of bilateral manipulation of talocrural joints on standing stability in healthy subjects. Man Ther 2009;14:75-80.

28. Pertille A, Macedo AB, Dibai Filho AV, et al. Immediate effects of bilateral grade III mobilization of the talocrural joint on the balance of elderly women. J Manipulative Physiol Ther 2012;35:549-555.

29. Martinelli AR, Mantovani AM, Nozabieli AJ, et al. Muscle strength and ankle mobility for the gait parameters in diabetic neuropathies. Foot (Edinb). 2013;23:17-21.

30. Nordahl SH, Aasen T, Dyrkorn BM, et al. Static stabilometry and repeated testing in a normal population. Aviat Space Environ Med 2000;71:889-893.

31. Rogers RG. The effects of spinal manipulation on cervical kinesthesia in patients with chronic neck pain: a pilot study. J Manipulative Physiol Ther 1997;20:80-85.

32. Pickar JG. Neurophysiological effects of spinal manipulation. Spine J 2002;2:357-371.

33. Heikkilä H, Johansson M, Wenngren BI. Effects of acupuncture, cervical manipulation and NSAID therapy on dizziness and impaired head repositioning of suspected cervical origin: a pilot study. Man Ther 2000;5:151-157.

34. Haavik H, Murphy B. Subclinical neck pain and the effects of cervical manipulation on elbow joint position sense. J Manipulative Physiol Ther. 2011;34:88-97.

35. Haavik-Taylor H, Holt K, Murphy B. Exploring the neuromodulatory effects of the vertebral subluxation and chiropractic care. Chiropractic J Aus 2010;40:37-44.

36. Dunning J, Rushton A. The effects of cervical high-velocity low-amplitude thrust manipulation on resting electromyographic activity of the bicepsbrachii muscle. Man Ther 2009;14:508-513.

37. Fernández-Carnero J, Fernández-de-las-Peñas C, Cleland JA. Immediate hypoalgesic and motor effects after a single cervical spine manipulation in subjects with lateral epicondylalgia. J Manipulative Physiol Ther. 2008;31:675-681.

38. Murphy BA, Dawson NJ, Slack JR. Sacroiliac joint manipulation decreases the H-reflex. Electromyogr Clin Neurophysiol. 1995;35:87-94. 
39. Fernández-de-Las-Peñas C, Alonso-Blanco C, Cleland JA, et al. Changes in pressure pain thresholds over C5-C6 zygapophyseal joint after a cervicothoracic junction manipulation in healthy subjects. J Manipulative Physiol Ther 2008;31:332-337.

40. Woolf CJ. Central sensitization: uncovering the relation between pain and plasticity. Anesthesiology 2007;106:864867.

41. van der Wurff P, Hagmeijer RH, Meyne W. Clinical tests of the sacroiliac joint. A systematic methodological review. Part 1: Reliability. Man Ther 2000;5:30-36.

42. van der Wurff P, Meyne W, Hagmeijer RH. Clinical tests of the sacroiliac joint. A systematic methodological review. Part 2: validity. Man Ther 2000;5:89-96.

43. van der Wurff P. Clinical diagnostic tests for the sacroiliac joint: motion and palpation tests. Aust J Physiother. 2006; 52:308.

44. Robinson HS, Brox JI, Robinson R, et al. The reliability of selected motion- and pain provocation tests for the sacroiliac joint. Man Ther 2007;12:72-79.

45. Arab AM, Abdollahi I, Joghataei MT, et al. Inter- and intraexaminer reliability of single and composites of selected motion palpation and pain provocation tests for sacroiliac joint. Man Ther 2009;14:213-221.

46. Bankoff ADP, Ciol P, Zamai A, et al. Study of body postural balance through the electronic baropodometric system [Portuguese]. Revista Conexões 2004;2:87-104.
47. Villani C, Mantenga N, Persiani P, Rijo P. Baropodometric assessment of metatarsal pain [Italian]. Chir del Piede 2000;24:1-10.

48. Guiotto A, Sawacha Z, Guarneri G, et al. The role of foot morphology on foot function in diabetic subjects with or without neuropathy. Gait Posture 2013;37:603-610.

49. Sawacha Z, Gabriella G, Cristoferi G, et al. Diabetic gait and posture abnormalities: a biomechanical investigation through three dimensional gait analysis. Clin Biomech. 2009;24:722-728.

50. Tullberg T, Blomberg S, Branth B, Johnsson R. Manipulation does not alter the position of the sacroiliac joint. A roentgen stereophotogrammetric analysis. Spine 1998;23:1124-1128.

51. Orakifar N, Kamali F, Pirouzi S, Jamshidi F. Sacroiliac joint manipulation attenuates alpha-motoneuron activity in healthy women: a quasi-experimental study. Arch Phys Med Rehabil. 2012;93:56-61.

Address correspondence to: Roberto Méndez-Sánchez, PT, DO Department of Physical Therapy Universidad de Salamanca

$C /$ Donante de Sangre $s / n$ 37007, Salamanca Spain

E-mail: ro_mendez@usal.es 
Copyright of Journal of Alternative \& Complementary Medicine is the property of Mary Ann Liebert, Inc. and its content may not be copied or emailed to multiple sites or posted to a listserv without the copyright holder's express written permission. However, users may print, download, or email articles for individual use. 